ENABLING ACCESS

TO NON-FOOD ITEMS

IN AN EMERGENCY

RESPONSE

A review of Oxfam programmes

\title{
SUZANNE FERRON
}

\section{PUBLIC HEALTH AND WASH CONSULTANT}

The objective of this review is to get a better understanding of the extent and effectiveness of NFI distributions in Oxfam's emergency responses. The findings of this review will be used to make recommendations for programme policy and guidance to maximize the impact of NFI distribution or alternatives in future responses. 


\section{CONTENTS}

Acronyms

Executive summary

1 Introduction

2 Findings from review of Oxfam documentation and key informant interviews

3 Information from other agencies

4 Gaps in review and further questions

5 Recommendations

6 Appendix 


\section{ACRONYMS}

\begin{tabular}{|c|c|}
\hline CBP & Cash-based programming \\
\hline CFW & Cash for work \\
\hline CTC & Child to child \\
\hline EFSVL & Emergency Food Security and Vulnerable Livelihoods \\
\hline EMMA & Emergency market mapping analysis \\
\hline HECA & Horn, East and Central Africa \\
\hline ICRC & International Committee of the Red Cross \\
\hline IFRC & International Federation of the Red Cross \\
\hline IRC & International Rescue Committee \\
\hline ITS & Informal tented settlement \\
\hline KII & Key informant interview \\
\hline LCB & Lake Chad Basin \\
\hline LMMS & Last Mile Mobile Solutions \\
\hline MBA & Market-based approach \\
\hline MEAL & Monitoring, evaluation, accountability and learning \\
\hline MHM & Menstrual hygiene management \\
\hline NFI & Non-food item \\
\hline MPG & Multipurpose cash grant \\
\hline NGO & Non-government organization \\
\hline OGB & Oxfam Great Britain \\
\hline OPAL & Oxfam Programme Accountability and Learning software \\
\hline PCMA & Pre-crisis market mapping and analysis \\
\hline PDM & Post-distribution monitoring \\
\hline PHP & Public health promotion \\
\hline RTE & Real-time evaluation \\
\hline SARC & Syrian Red Crescent \\
\hline WASH & Water, sanitation and hygiene promotion \\
\hline
\end{tabular}




\section{EXECUTIVE SUMMARY}

This review aimed to get a better understanding of the extent and effectiveness of non-food item (NFI) distributions in Oxfam programmes, in order to develop recommendations for programme policy and guidance to maximize the impact of NFI distributions or alternatives in future responses. Documentation relating to 15 recent WASH responses was examined and key informant interviews were conducted with some of the key Oxfam staff involved in these responses.

People affected by crises often require a wide range of NFI. Access to these items is usually facilitated by different response sectors, particularly Water, Sanitation and Hygiene Promotion (WASH), Food Security and Shelter. More recently, Gender and Protection actors have also started providing NFI in the shape of dignity and safety kits.

All Oxfam's humanitarian WASH responses consider the provision of NFIs as a key programme intervention, and the vast majority employ in-kind blanket distributions. No programme had considered the option of not providing hygiene items (except perhaps to certain areas) or of deliberately providing them later in the response rather than immediately (although provision was often delayed). The impact of delayed hygiene kit distribution is not known.

The implementation of in-kind distributions, including registration and verification, is expected to be the remit of Public Health Promotion (PHP) teams. However, both the Typhoon Haiyan and the Nepal Earthquake real-time evaluations (RTEs) stressed the importance of identifying distribution managers and teams to lead this work, so that other important PHP work was not delayed. Many key informants stressed the importance of ensuring that there were staff dedicated to in-kind distribution, but a key informant from logistics did not feel that this community intervention should fall under their remit.

It is reported that NFI needs assessments are undertaken in most responses, but this does not always identify people's preferences, and the resulting hygiene kits tend to be very similar. The quality and usefulness of post-distribution monitoring (PDMs) was questioned by numerous key informants and it is clear that guidance on their development and use is required to ensure that they capture more useful and reliable information, and also that they are prioritized in situations where they can influence decisions about programming. It may also be useful to include questions about market access in PDMs. Closer collaboration on monitoring between PHP and Monitoring, Evaluation, Accountability and Learning (MEAL) teams is also necessary.

While cash-based programming (CBP) has been used in the WASH sector for many years in the shape of cash for work or water vouchers, only five current responses are using hygiene vouchers. None of these have been introduced in the first phase of the response and none are done at scale. It is clear that there is much more scope for the use of CBP in WASH.

All key informants in Oxfam and other agencies welcomed the advent of CBP (and the broader use of market approaches) and recognized the positive impact it can have on people affected by emergencies, and on their own practice. However it was acknowledged that field-based staff often become tied into implementing in-kind distributions for a variety of reasons. For example: an initial assessment that markets are not functioning and will take a long time to re-establish; the need to use existing contingency stocks or continue with procurement orders; the pressure to scale up quickly and reach large numbers; the perception that distribution is faster to implement; and a perceived lack of capacity and experience to use cash transfers.

Market assessments are currently seen as very lengthy processes. There is the perception that it is possible to simplify these so that they are more suited to a rapid response, or provide more accessible and practical information that can inform decisions about programming. Very few of 
the reviewed programmes had conducted a market assessment in the early stages of the emergency, but several were planned for subsequent phases where responses were ongoing.

Some key informants remain concerned that people will not prioritize hygiene items and that, therefore, cash is not appropriate; but there is currently inadequate information to confirm or refute this fear and it is likely to be different in different situations. It is also the case that evidence on the effectiveness of hygiene kit distribution is currently inadequate so more evidence is needed of the impact of different choices on public health.

Public health goals were not the only reason why hygiene items were provided. Many informants emphasized that they were a means to ensure dignity.

Several key informants stressed the importance of using public health and epidemiological analysis to inform NFI distributions in WASH responses, in conjunction with an understanding of people's preferences and intra-family dynamics, in order to help determine what modalities were most appropriate. In some situations such as disease outbreaks, in-kind distributions (e.g. of household water treatment) or commodity vouchers may be preferable to value vouchers or cash, but it should not be assumed that this applies to every situation.

\section{OXFAM INTERNAL RECOMMENDATIONS}

\section{General}

- The need for hygiene items and response objectives in each specific context should be clearly stated and the argument for not using cash must be clearly documented.

- Needs assessments should identify what people are using already and consider the likely epidemiological risks and feasibility of current practice, before considering NFI provision as a useful response. It may not always be necessary to provide NFIs.

- Preparedness data, such as pre-crisis market mapping and analysis (PCMA) or Framework Agreements with suppliers, for a particular location can help to inform the immediate response, but monitoring will need to become more sensitive and pragmatic.

- Investigating the use of multi-purpose cash grants is to be encouraged wherever feasible as an early response, as this modality is more likely to contribute to improving dignity than the provision of in-kind hygiene items and can be combined with other modalities. If using multipurpose grants, the differential impacts need to be closely monitored to ensure that women are still able to manage their menstruation adequately and that hygiene needs are met for different family members.

- It is possible that limited in-kind distributions will continue to be necessary in some contexts and for some items only where public health risks are high, such as a disease outbreak or where markets are not functioning.

- While country programmes are expected to develop the terms of reference for evaluations and to identify the key issues for the focus of the evaluation, the current spend on NFIs and the lack of research on the use of cash and multi-purpose grants to achieve WASH goals warrants a more systematic inclusion in all RTEs and evaluations.

\section{In-kind distributions}

- Contingency planning for in-kind WASH-related distributions needs to involve the PHP team, Logistics, and Senior Management at global, regional and country level. 
- Where hygiene items are judged to be necessary and where in-kind distribution is assessed to be the best ${ }^{1}$ alternative, the provision of a basic hygiene kit only is recommended, rather than a kit that seeks to meet every identified need.

- A phased response to the provision of NFIs may work better than the current approach, so that priority needs are met initially with a small in-kind distribution (where markets are not functioning) but the $\mathrm{NFI}$ response can evolve as the context evolves - if hygiene items continue to be required.

\section{Process issues for in-kind distributions}

- The recruitment of a distribution manager and distribution teams should be given high priority in a large-scale emergency where distributions in kind are expected. It will probably be necessary for WASH staff in the field and at HQ to continue to lobby for this to be incorporated into budgets and planning. It may be necessary to map out more clearly the respective roles and responsibilities of different programme staff and ensure that programme managers encourage collaborative working.

- Experience seems to have shown that people are often not listening to the 'public health' information provided at the time of a large-scale distribution, and this strategy must be reviewed.

- Procedures for post-distribution monitoring also need to be reviewed, and more detailed guidance provided to field staff. There is a need for greater involvement of PHP in the design and analysis of monitoring studies, and the PDM process needs to be incorporated into programme plans. Questions relating to market access could usefully be included in PDMs.

- A multi sector approach to the provision of in-kind NFIs (as with the provision of multipurpose grants) probably makes for a better experience for recipient families and communities, rather than simply focusing on specific hygiene or protection needs. It is important that this is seen as a programme issue, rather than a sector issue.

- More information is needed on the development of a 'distribution kit' to support the setup and management of in-kind distributions.

\section{Market-based approaches (MBAs)}

- Ideally all responses should incorporate market assessments (including in-kind distributions) and the decision about which tools can best meet the needs of the population should only be made following such an assessment.

- PHP staff are encouraged to always look for opportunities for CBP, even if on a very small scale and even if this means using both in-kind and cash modalities simultaneously, in order to build confidence and capacity.

- The current use of cash grants by Emergency Food Security and Vulnerable Livelihoods (EFSVL) should include monitoring of if, what and why people prioritize (or do not prioritize) WASH-related items.

- The advent of multi-purpose grants paves the way for more integrated working between sectors, and could ultimately lead to a less fragmented approach to meeting the NFI needs of affected populations. These will need to be monitored carefully to ensure that they address public health risks and meet the needs of the most vulnerable, as well as improve dignity and choice. 


\section{FURTHER QUESTIONS}

- Further investigation into the provision of NFIs and the modalities for doing so is also needed to identify how coordination, targeting and cross sector collaboration can all be improved, as well as to explore the following questions:

a. Is overall global proportional humanitarian spend on NFIs increasing, or is this just the perception of key informants?

b. What opportunities are there for interagency collaboration on improving the approach to ensuring access to NFIs?

c. How can the evidence base for the distribution of hygiene kits and the use of alternative modalities be developed?

d. How can coordination of the provision of NFIs and/or alternatives be improved? (How should/does Oxfam/ other WASH NGOs coordinate with the shelter sector on this?)

e. What policy do donors have on funding and stockpiling NFIs or alternatives?

f. How are NFIs targeted in Oxfam and other organizations, and does targeting make sense in contexts where it will be redistributed anyway?

g. Can/should cash (or MBAs) be used as an incentive for behaviour change, and how?

h. How can epidemiological data be better used to rationalize NFI interventions? (The table in the appendix attempts to consider the different factors involved in deciding if NFIs are necessary).

i. What additional guidance and support is required to support field staff?

- Where more detailed pre-crisis analysis is possible, this information needs to be presented in a form that is more accessible to field staff. Exploring ways to simplify market assessments to make them more feasible in an acute emergency response will also be important, and collaboration with other agencies on this is likely to be critical.

- More research is needed to explore how MBAs such as the use of a partial subsidy rather than a full subsidy (e.g. market offers or discounts, such as 'buy one get one free') can be used to influence consumer behaviour in emergency contexts.

- Further discussions are needed with the Shelter Cluster on the coordination of NFIs and how this can be improved.

- Discussions are also needed with donors who have pre-positioned stocks, to ensure that the offer of these does not undermine the use of MBAs. 


\section{INTRODUCTION}

This review aims to understand how effectively Oxfam is supporting people's access to NFIs in humanitarian responses - either through in-kind distributions, or the use of cash transfers (including vouchers).

Although it focuses primarily on Oxfam humanitarian responses, some of the issues raised by internal and external respondents are relevant for broader consideration by those involved with in-kind distributions or alternatives in the humanitarian sector as a whole.

Information for the review is drawn from internal Oxfam documents, including programme reviews, proposals, sitreps, evaluations and PDMs, as well as published studies and reports by Oxfam and other aid agencies. Interviews were also held with a variety of key informants from Oxfam and other agencies.

\subsection{THE NEED FOR THE REVIEW}

Although it only represents a relatively small percentage of the overall spend on programmes, the spend on NFIs in Oxfam programmes is considerable - amounting to an average yearly total spend in the last 10 years of approximately $£ 7$ million. There is also a perception that the number of NFI kits being distributed has increased significantly over recent years. It is therefore important to ensure that this aspect of programming is meeting people's needs, ensuring public health impact, and being carried out in an effective and efficient manner.

Numerous actors are concerned that the distribution of in-kind NFIs does not always achieve its objectives, that it distracts the PHP team from focusing on listening to and working collaboratively with communities, and that it perpetuates a paternalistic dynamic from the very start of the response, thereby undermining the development of a more equal relationship with communities and creating dependency.

\subsection{THE RATIONALE FOR PROVIDING NFIS IN AN EMERGENCY}

The provision of NFIs - whether in kind or using cash and vouchers - is seen as a way to meet the felt needs of the population, enhance their sense of dignity, and particularly in WASH responses, contribute to public health - primarily by preventing disease. To a certain extent these objectives are interrelated. For example, there is no point in providing clean water if people are not able to collect and store the water in clean containers, or wash their hands with soap (both contributing to a sense of dignity as well as preventing disease).

The actual evidence for the impact of a distribution of NFIs on public health is limited. Peterson et al (1998), examining the effectiveness of soap distribution in a Mozambican refugee camp in Malawi, found that:

'The provision of regular and adequate soap rations, even in the absence of a behaviour modification or education programme, can play an important role in reducing diarrhoea in refugee populations.'

However a recent systematic review by Ramesh et al (2015) failed to identify further studies to confirm this finding. A recent evidence synthesis that included available grey literature also 
failed to find any evidence of the impact of hygiene kit distribution, and only low to moderate evidence when this involved household water treatment (Yates et al 2017).

There are no published studies on the impact of the provision of hygiene kits on improving dignity.

\subsection{NFI NEEDS AND PREFERENCES}

In different countries, responses and contexts, women, men and children of different family size, age and ability have different needs for NFIs.

However, as discussed below, kits (particularly hygiene kits) in a specific response are often very similar and may be standardized across agencies - meaning they are less likely to meet the varied needs of the population or of individuals within each family.

The advent of the use of cash and vouchers ${ }^{2}$ in the food security and nutrition sector has paved the way for the use of these modalities in other sectors (where feasible). It is argued that this allows people to have greater choice and to obtain the NFIs that they actually want and need, and to respond to different family needs. It also avoids the indignity of and time spent waiting in a distribution queue, and potentially has other positive benefits for local markets and the economy.

The alternative view is that providing people with free choice in the selection of NFIs may mean that they will not always prioritize items that can have a public health impact, like soap or clean water containers. However this argument applies equally to distributions in kind or cash, as people can choose not to use the items that are provided, and may sell or barter them or simply keep them for another purpose (e.g. as a dowry or asset.)

\subsection{PROVISION OF IN-KIND NFIS}

Despite the success of CBP in the food security sector, this modality may not always be possible, as markets may not always be working or accessible, and in-kind distribution will sometimes be necessary.

Different types of NFI kits have proliferated over the years: hygiene kits (e.g. soap, water containers, toothbrushes, combs and MHM materials); water kits (e.g. jerry cans and household water treatment); dignity kits (e.g. MHM materials, underwear); kitchen kits; shelter kits; solid waste management kits; winterization kits; and most recently, safety kits (identified by Protection teams with the aim of providing items that might contribute to safety such as solar lights, phone chargers, whistles and padlocks).

The kits are not globally standardized, so a dignity kit will not always have the same contents everywhere, but there is a tendency for them to be very similar in each country response. They may even be standardized following discussions in coordination meetings. Arguably, standardized kits are logistically easier to manage - both in terms of contingency stocks and distributing quickly to large numbers of people - and fairer, ensuring a more equal response.

Most kits are provided on a household basis, but some kits such as those for latrine cleaning, environmental health or safety are often provided for a specific community or group, and are perhaps logistically easier to distribute over time on a case-by-case basis and in smaller numbers. 
In the WASH sector, hygiene kits are usually provided as a first-phase response in most emergencies, and hygiene promoters are often tasked with organizing and implementing the distribution - although this is not the case in all agencies. ${ }^{3}$

Overall coordination of NFIs is supposedly led by the Shelter sector, but the WASH sector has also articulated standards for personal hygiene items and water facilities - arguably encouraging the default distribution of hygiene kits, and leading to some fragmentation of coordination.

In the original Sphere Standards of 2004, the provision of hygiene items was included with other NFIs such as kitchen sets and bedding, as part of the Shelter Standards. Since the 2011 revision of the standards, the identification and use of hygiene items has been incorporated a separate standard in the WASH Chapter. The provision of 'water use facilities and goods' (e.g. water containers), however, has consistently been included in the WASH Standards. 


\section{FINDINGS FROM REVIEW OF OXFAM DOCUMENTATION AND KEY INFORMANT INTERVIEWS}

Documentation relating to 15 recent WASH responses was examined (see table in appendix for a list of responses), and key informant interviews (KIls) were conducted with some of the key Oxfam staff involved in these responses. (Three PHP Advisors, five PHPs, one Logistician, three Programme Managers, one MEAL Manager, and one Markets Advisor.) In addition various reports relating to $\mathrm{CBP}$ and the WASH sector were also reviewed. Interviews were also held with four key informants from other agencies.

\subsection{SPENDING ON NFIS}

In the financial year 2016, the total spend on all NFIs in Oxfam GB was almost $£ 9$ million comprising four percent of the total programme spend. The total spend on all Hygiene and Health NFIs (the latter includes water containers, hygiene kits, soap, oral rehydration solution, mosquito nets) for the 2016 financial year was over $£ 4$ million. Cooking sets, tarpaulins, tents, shelter kits, stoves, clothes and blankets make up the 'other' spending on NFIs.

Over the last 10 years, spending on NFls appears to have gradually increased, with annual spending on health and hygiene since 2010 at approximately $£ 5$ million. Before 2010 , annual spending amounted to approximately $£ 2$ million. This could be due to an increase in responses or funding, but the percentage spend on health and hygiene NFIs also seems to be increasing. The figures given above do not include costs associated with staffing, procurement, storage, transport and distribution.

Spending on cash programming has more than doubled each year since 2011, with spending for FY2016 being $£ 15,420,533$, including $£ 305,159$ provided as cash grants to partners. This spending is predominantly related to EFSVL programming. ${ }^{4}$

\subsection{IN-KIND DISTRIBUTIONS}

In-kind distributions were carried out during the first phase in all of the responses reviewed. Indeed, it was assumed that this was a crucial aspect of the initial response by several key informants. Several informants saw it as the default response because it 'makes us feel we are doing something'. It was also suggested several times that it was an effective way of 'boosting the programme coverage quickly'.

Some respondents felt that it was a useful 'entry point into communities', and better to be able to provide something during the assessment 'rather than just ask questions'. This had been done in South Sudan and Pakistan. However, it was not clear how widespread the practice of assessing and distributing at the same time was.

For most key informants, the provision of hygiene NFIs was seen as an issue contributing to dignity first and foremost: If you are clean you just feel better,' but often having a minimal impact on public health except in disease outbreaks such as a cholera response. 
The provision of NFIs was often seen as most useful in situations where people had been displaced and had arrived with nothing (e.g. first-phase distribution of shoes and clothes in the Europe response, in Nigeria for new camp arrivals). However, if people were in transit they sometimes chose to leave behind half the items' they were given (e.g. hygiene kits in the Europe response). In June/July 2015 in Nyal, South Sudan, where access has often been very difficult, NFI items (minimal contents: jerry cans, water purification sachets) were air-dropped onto the islands where people were hiding.

For several key informants, the number of different kits was perceived to be increasing, especially with the advent of specific gender- and protection-focused programming. Dignity kits and safety kits had been incorporated into several recent responses (Nigeria, South Sudan and Philippines).

The contents of the kits were seen to be dependent on available funding and speed of procurement, with the better-funded responses able to afford more comprehensive kits. Where procurement was slow, a kit was put together on the basis of what was available. Although this does not mean that the items were not seen as useful, it does suggest that the provision of kits is probably not always responding to expressed needs.

\subsubsection{Standardization}

The issue of standardization of kits was considered in both a positive and negative light. It was seen as necessary to standardize kits for numerous reasons:

- To ensure manageability by logistics teams

- To ensure rapid delivery

- To coordinate better with other agencies

- To provide the possibility of joint procurement (with corresponding savings of time and money)

- To ensure minimum requirements.

In several situations, hygiene kit contents were standardized with other agencies through the WASH Cluster or other coordination structures.

In the recent Aleppo response, the WASH Cluster agreed on the use of 'mini kits' of basic items. These consisted of only four items: soap bars, washing powder, shampoo and sanitary pads.

However, for some respondents, standardization of kits was an indication that ongoing assessment of the need for different hygiene items, and even post-distribution monitoring of gaps, was to some extent redundant as there was little likelihood that significant changes to kit contents would be practical or could even be made at short notice.

\subsubsection{Procurement}

In an acute emergency, minimum requirements for procurement will usually apply - avoiding the need to adhere to normal tendering processes and allowing for a more rapid response. This 'can take anywhere from two to five weeks or even longer in some situations'.

'Distribution is the default position. We do it because it makes us feel better.'

- HQ staff member

However the value of the goods requested may be more than the minimum requirements, necessitating the use of tendering. It is preferable that framework agreements are in place with selected suppliers before an emergency, so that orders can be responded to quickly and flexibly. 
According to key informants, delays in procurement were frequent in many responses, but not for every location in the same response. Some responses managed to start distributing very quickly if pre-positioned stocks were available (Tacloban in the Typhoon Haiyan response using UNICEF stocks). In several situations, incomplete kits were distributed as it was thought better to distribute something rather than wait for the missing items.

In some cases there had been a delay in distribution (South Sudan), despite procurement of kits with kits sitting unused in the warehouse.

Wherever possible, procurement had been done locally, but regional procurement was also common. International procurement for hygiene kits was far less common. Gifts in kind were also received from Irish Aid in several responses (Philippines, South Sudan, Iraq and Niger) and from UNICEF (Philippines), usually from regional stockpiles. Unilever had also provided donations of soap in some responses (Philippines) and Little Sun Gmbh of solar lamps (South Sudan). While many of these 'gifts in kind' had been requested by the programme and were seen to be appropriate and useful, there were also concerns that their existence undermined the use of local markets.

\subsubsection{Implementation}

The NFI distribution plans for two recent responses (Nepal and Sierra Leone) appeared to be very comprehensive - paying attention to the needs of the most vulnerable, incorporating feedback desks and crèches. The Nepal EQ NFI distribution had women-friendly areas, also with various activities for women, and included dialogue platforms and children's corners. Initial in-kind distributions had been quite chaotic but the development of a distribution equipment kit had helped to support the organization of subsequent distributions. More information is required on the usefulness of a distribution kit.

However, the RTE from the Papua New Guinea El Niño drought response points out that the needs of women and people with disabilities were not considered during distributions.

Several respondents discussed the need to rethink the process of the distribution and especially the provision of promotional activities, expressing similar concerns that 'people are just not listening', 'it is inappropriate to provide messages at this time', 'it is always very rushed'.

Some felt that people did not need information on how to use the items in the kit as this was obvious, although others did explain that people did not always recognize that, for example, a bucket had been provided to enable hand washing or for water storage: 'Sometimes when you visit the household the bucket is used by the pigs or donkeys'. Examples of the misuse of sanitary towels in Pakistan and Sudan have also been documented where men and women were unclear of their purpose.

It could be argued that it would make little difference to the subsequent use of hygiene items whether or not information about their use was provided and what is more important is to discuss this during subsequent household visits and community group discussions - when there is time for people to reflect and ask questions. The provision of information during in-kind distributions needs to be reviewed to ensure that opportunity for communication is used as effectively as possible.

One respondent (from Protection) pointed out how important it was to conduct a risk assessment before carrying out a distribution, by simply asking teams to reflect on what could go wrong, and putting in measures to avoid such problems. Another respondent mentioned the involvement of the security advisor to help identify and mitigate risks by reviewing the process and physically viewing the location of the distribution. In the time available, it was not possible to get an accurate assessment of how many programmes carried out a risk assessment prior to distributions or whether protection and safety issues were a common cause for concern. 
The question was also raised by one key informant about the distribution of non-hygiene related NFIs by the PHP teams and whether this was acceptable. For example in the Syria response, PHP teams have been responsible for the distribution of Winterization kits.

\subsubsection{Distribution teams}

Several respondents and various documents mentioned the drain on PHP time of doing largescale distributions. It was not only the actual distribution that took time, but also the registration and verification.

The use of distribution teams seemed to be very limited in the reviewed programmes. In most cases, registration, verification and distribution were seen to be part of the normal PHP workload. Two key informants recommended that distribution should continue to be managed by PHP as they felt this was an important and relevant part of their work.

The Typhoon Haiyan RTE noted that:

'The delay in setting up distribution teams has had a detrimental effect on the sequencing of the PHP activities. The field teams are now carrying out their training of community health volunteers, barangay health workers, and WASH committees - two months after the typhoon.'

However one respondent in this response had lobbied for the inclusion of distribution teams in the budget and always insists on this in other responses - noting that 'it is often omitted from budgets and programme plans'. She had recruited two distribution officers in the Typhoon Haiyan response who were then supported by a team of volunteers, and argued that she has not found much resistance to this, as these are usually only short-term positions.

Another key informant had also argued for logistics assistants to support in-kind distributions (Nigeria), but the decision was made to hire logistics personnel with a more general skill set instead, on the basis that distributions were a short-term intervention and dedicated distribution assistants would not be utilized enough.

While an HSP Distribution Officer has been recruited by the Logistics Department in Oxford with a remit to support distribution, their job description points out that they are there to 'coordinate all those (incl. Oxfam, partners and volunteers) who are supporting distribution activities', rather than necessarily to manage NFI distributions and recruit staff to implement them.

A respondent from the logistics team felt that it would not be desirable for the logistics department to be involved in actual distribution. He felt that their responsibility involved procurement and transport but that they did not have adequate knowledge of communities and field realities to make distribution an effective use of their time. The use of logistics teams to manage actual distributions was also perceived as involving duplication and overlap with other field teams - meaning that they would need to familiarize themselves with community structures and processes.

'In-kind requires the entire PHP technical team to run the distribution.'

- PHP HSP

Another respondent (programme management) explained that in contrast to other organizations such as MSF, Oxfam does not recruit 'field logisticians' but rather 'admin logisticians' and therefore they do not have the knowledge of the field that is necessary to be able to manage distributions.

\subsubsection{Timing of distributions}

The timing of distributions seemed to be very variable - both between and within programmes with some able to start distributing very quickly and others being delayed because of delays in 
procurement, problems with access or the lack of programme staff. However, detailed information on every response was not available.

Several key informants had come across situations where delays had led to NFIs being distributed very late - some after six months of programming (dignity kits in Typhoon Haiyan, some cholera kits in South Sudan). One key informant said that it was important to know when to stop' and to have a cut-off point after which the use of in-kind distributions would need to be clearly justified as a response in the changed context.

\subsubsection{Collaboration within Oxfam on in-kind distributions}

As has been previously noted, a variety of personnel and teams are often involved in NFI distributions. Logistics teams support procurement and transport, and an HSP Distribution Manager has recently been recruited. Collaboration and communication between Logistics and field teams was seen to be vital if distributions were to be carried out efficiently and effectively. There was some frustration voiced by both PHPs and Logistics about the lack of effective communication between them, and reluctance to be involved in NFI distributions. It is sometimes perceived that PHP is expected to know about things that are assumed to be the expertise of Logistics teams (such as the size of trucks required for a distribution).

Some respondents noted the recent involvement of Protection and/or Gender teams in NFI distributions. This has become more likely as Protection and Gender standalone programmes have become more common. There are differences of opinion as to whether the involvement of these teams in any distribution is appropriate, and it is possibly better if they work through other teams to ensure that existing distributions meet the needs for dignity and safety. There are several examples of the involvement of Protection teams or focal points from Horn, East and Central Africa (HECA), but most of these examples involve supporting other teams to meet community needs, rather than standalone distributions.

\subsection{COORDINATION}

Most respondents could cite examples of where duplication of NFI distributions had occurred sometimes thought to be as a result of people registering twice.

An Oxfam market assessment following Typhoon Haiyan identified significant duplication in the distribution of hygiene kits. In one region, the results of a household survey revealed that more than half of households had received four hygiene kits from different agencies. All areas had received more than one kit.

One respondent talked about the existence of a separate 'NFI Cluster' in some responses, but it is likely that this is overseen by the Shelter Cluster as NFIs come under their remit. The same respondent said that she didn't have time to go to such coordination meetings - meaning that coordination problems and duplication were possible.

Coordination was seen as particularly problematic in large-scale emergencies and/or where there were many new players (Middle East). The Ebola response in West Africa was also seen as particularly difficult, as affected communities would not always admit to having received items already. This is perhaps unsurprising given the fact that livelihoods had been disrupted. 


\subsubsection{Post-distribution monitoring (PDMs)}

While some key informants felt that PDMs had improved over time, many questioned the usefulness of them and felt they were often self-fulfilling - asking leading questions and with many failing to capture useful information that could feed into programme adaptation quickly enough. They seemed to rely predominantly on quantitative data that was not triangulated. One informant suggested that there was not enough involvement of PHP in selecting the questions and identifying the recommendations. However, the stipulation that MEAL and PHP team leaders decide on the recommendations is articulated in an existing 'roles and responsibilities' document, but it may be that not all staff are aware of the guidance available on this.

Most of the PDM reports that were reviewed had been carried out within two weeks of the distribution, although there were sometimes delays in circulating reports and even in carrying out the monitoring (Nepal).

While there were examples of how PDMs had influenced programmes, the general feeling seemed to be that the mechanism needed a radical overhaul and that more guidance on their use and application was required. It is not necessary to conduct a household survey after each distribution - nor to ask all of the current questions - interrogating the quality of each item. A small number of focus group discussions (FGDs) could be carried out instead, and/or questions on accessibility and use of markets to obtain items could be included.

In one programme example from Pakistan, a matrix ranking exercise was used (by the PHP team) as a way to identify priority hygiene items and to obtain qualitative information on people's perceptions and preferences. This led to a more nuanced and different response in different districts.

Exit interviews following in-kind distributions similarly were not seen to be particularly useful (Iraq Mosul response particularly) as people will often not want to appear overly critical when they have just received something.

\subsection{NEEDS AND MARKET ASSESSMENTS}

NFI needs assessments were said to have taken place in all the responses reviewed and several informants insisted that NFIs were distributed 'according to needs'. However, some key informants were more sceptical, and felt that distribution was dictated by donor funding, available stocks, and even sometimes by the need to demonstrate that the programme was scaling up quickly. The only available assessment reports were those from the Europe response, and they identified general rather than specific NFI needs.

Emergency market mapping analyses (EMMAs) were considered to be too time-consuming to initiate in the first phase of an emergency, and several key informants felt that they could and should be simplified. Very few market assessments had been carried out in the recent WASH responses that were reviewed, but several were being planned.

It should be borne in mind that any kind of resource transfer can have an impact on markets including in-kind distributions - but no market assessments of potential impacts were carried out before the implementation of in-kind distributions. Some negative impacts of in-kind distributions are also highlighted in recent PCMAs. ${ }^{5}$

It was felt by some that a key issue was the poor quality and lack of cross-sector integration of needs assessments, and the fact that they did not ask specific questions about NFIs - rather, where there were cyclical responses, pre-existing data was used on NFI needs and preferences 
and the response was based on what had always been done. The need for collaboration between agencies and more multi-sectoral assessments was also highlighted.

The PCMAs identified that in some situations people already had the NFIs that were being distributed, or preferred alternative items and sometimes kept back some items for future dowries. It was suggested that in recurring emergencies, people may even come to rely on the free distributions of relief goods and not buy items that they were actually able to afford, e.g. household water treatment in Zimbabwe.

The PCMA from Bangladesh was very revealing and identified information that should have been collected by the PDM mechanism - such as the fact that women preferred soap powder to laundry soap as it was easier to use and ration, or that the saris that were intended to free up older material for MHM were never used in this way - even when women were displaced - as they would take what they required with them. Although there is the potential for PCMAs to look in-depth at NFI needs before a crisis (thus requiring only minimal validation post-crisis), the reports were seen as being too long and not always as useful and accessible as they might be.

In Jordan, shopkeeper assessments were reported to have been done very quickly and in Nepal one programme manager simply kept asking the team to find out if items they were ordering were available in the market first - indicating that more rapid means of assessments are possible.

\subsection{TARGETING}

Very few WASH NFI interventions had involved targeting and most were blanket distributions where everyone was perceived to be in need - especially in the first phase. However, the provision of NFIs - and indeed WASH programming as a whole - was often targeted to specific areas or settlements perceived to be at risk or vulnerable. This is in contrast to EFSVL where even in vulnerable areas the most vulnerable households will be targeted.

In one response (Nigeria), targeting became necessary because the assessment and subsequent procurement had significantly underestimated population figures, so that the intended blanket distribution was not feasible. This led to delays in provision because the vulnerability assessment took time and by the time of implementation, 'most people had found a coping mechanism'.

Some respondents reported that while they had used a blanket approach in the early acute phase, a subsequent targeted approach in later stages of the response was usually recommended.

One informant pointed out that in some communities, aid workers can go to great lengths to target, but redistribution is often likely afterwards as people apply their own interpretation of what needs to be done with goods or cash received. Blanket distribution was seen by some commentators to be preferred in an emergency as targeting risks errors of inclusion and exclusion. 


\subsection{CASH AND VOUCHERS}

Only three of the reviewed responses (Lebanon, Jordan and Myanmar) were (or had been) using hygiene vouchers (some value-based and some commodity-based) and none had used this modality in the early stages of the response. This was said to be due to a variety of reasons:

- Markets not functioning or inaccessible (Nepal, Philippines, Niger)

- Perceived to be quicker to distribute in kind to large numbers of people (South Sudan, Nepal, Nigeria)

- Orders already placed for NFIs (Nepal)

- Stocks or donations of in-kind materials needed to be used up - and pressure from logistics to do this (Nepal, Pakistan, Nigeria)

- Pressure from donor to spend money quickly (LCB)

- Lack of in-country capacity (Pakistan, Nepal)

- Government resistance to use of cash (Europe, Syria)

- People too mobile and won't be able to monitor (Iraq)

- Time needed to conduct an EMMA

- Delays in recruiting staff with cash or markets expertise (Nepal).

In the few countries where CBP for WASH was being or had been used, this had been instigated some way into the response (sometimes a year or more later) and had taken time to put in place. In Myanmar and Haiti this was because the PHP coordinators were trying to incorporate this additional element into their existing workloads, and it was felt that with dedicated staff available, it could have been instigated much more quickly.

'Once we had arrived, al orders were in but in some areas markets were functioning, and it would have made more sense to use them.'

- PHP HSP

The opportunity to do CBP for hygiene kits within the first three months of the response was thought to have been possible in the following recent responses (in some but not all programme locations): Philippines Haiyan, Nigeria, Nepal EQ, Myanmar, Lebanon. At the very least it was thought that CBP could have been incorporated as a follow-on response to ensure the replenishment of consumables.

It was observed that often, despite an initial assessment that markets were not operating, this could change very quickly, and that Oxfam needed to be able to respond to these dynamic shifts in context.

From the review of several PDMs it was also clear that people were often prepared to walk a long way to access a distribution - sometimes over two hours - and therefore might be happier using vouchers and walking to a market if it afforded them more choice and independence.

The table below illustrates all the current humanitarian programme proposals where vouchers or cash are being used to support WASH interventions. It is a reflection of programme proposals and may not illustrate the full scope of current programming. 
Source: OPAL (Oxfam's programme management software)

\begin{tabular}{|l|l|l|}
\hline Country & Modality & Comment \\
\hline Jordan & Water voucher & $\begin{array}{l}\text { Previous interventions used } \\
\text { hygiene vouchers also }\end{array}$ \\
\hline Somalia & Water voucher & One location only (Cebu) \\
\hline Philippines & Water voucher & $\begin{array}{l}\text { Fuel and clothes only indicated in } \\
\text { proposal, but recent visit indicates } \\
\text { use of vouchers }\end{array}$ \\
\hline Lebanon & Hygiene voucher & Feasibility study \\
\hline CAR & Hygiene voucher & Planned response in proposal \\
\hline Myanmar & Hygiene voucher & $\begin{array}{l}\text { Proposal states possible use of } \\
\text { vouchers }\end{array}$ \\
\hline Nepal & MPG & $\begin{array}{l}\text { Proposal states possible use of } \\
\text { vouchers (Gaza) }\end{array}$ \\
\hline Yemen & Hygiene voucher & $\begin{array}{l}\text { Trialling of technology for urban } \\
\text { disaster }- \text { also doing cost-benefit } \\
\text { analysis of cash versus in-kind }\end{array}$ \\
\hline OPTI & Hygiene voucher &
\end{tabular}

One key informant suggested that both in-kind and voucher modalities are $100 \%$ subsidized and that the use of partial subsidies could be explored, e.g. providing offers or discounts for certain hygiene items. A study in Zimbabwe offered a 'buy one get one free' offer on household water treatment to consumers who had not been exposed to previous aid distributions, and preliminary results found more people buying at the full price after the intervention.

\subsubsection{Selecting the right modality}

The concern that people will not prioritize hygiene items has meant that PHP programmes have often argued for the use of commodity-based vouchers rather than cash distributions. However there is no evidence that people deprioritize hygiene in every situation, or that the provision of hygiene items do in fact have a critical impact on public health. Several key informants said that in many situations cash would be the preferable option, but that this decision should be influenced by an epidemiological assessment of risk and discussions with community members.

As with the provision of in-kind NFIs, recipients of vouchers may also decide to exchange or sell them below their market value to enable them to cover other priority needs.

The provision of multi-purpose grants as a first-phase response could also free up PHP time to identify gaps in provision for those who might be vulnerable, such as people with disabilities or older people, or to address specific needs such as managing incontinence. It would allow PHPs to spend more time discussing with communities and involving them in decisions about meeting their needs.

If vouchers are to be used, these should optimize opportunities for greater choice and flexibility if they are to offer significant advantages over in-kind or commodity voucher based-distributions. Where it is likely that specific items may reduce public health risk, e.g. in the event of a disease outbreak, it may be that more than one modality may be needed.

The Norwegian Refugee Council (NRC) provided value-based vouchers (with limited restrictions) to Syrian refugees as part of their response in Za'atari camp in Jordan, and found that two in three refugees were purchasing hygiene or cleaning items. 
In Jordan, Lebanon and Bangladesh, women expressed a preference for vouchers, as this gave them more say on what to purchase, whereas decisions about how to spend cash will often be made by a male head of household.

In the NRC study in Za'atari camp, cash was perceived as less safe than vouchers, but distributions were perceived as the least safe modality.

\subsubsection{Collaboration on the use of CBP}

The Logistics key informant felt that it would be critical that Logistics were involved in setting up any cash or voucher programmes - and indeed that they should be responsible for such programmes in order to ensure accountability and a segregation of duty between the identification of 'beneficiaries' and 'suppliers'. He also felt concerned that it would be difficult to ensure the quality of goods if numerous different suppliers were involved, and feared that this might be very labour-intensive.

Concerns about quality do not seem to have been articulated (by recipients) as an issue where vouchers have been used. If people are given a choice of suppliers to go to and of items to purchase, then presumably they would be the ones to determine an acceptable level of quality.

Several WASH key informants identified the need to work more closely with EFSVL colleagues, and examples were given of opportunities in the field for collaboration with registration and sometimes on targeting (Jordan, Lebanon, Iraq, Haiti EQ). However, EFSVL teams are understandably reluctant to assume the support for cash or voucher interventions for WASH, so appropriate investment of resources will be needed to facilitate better collaboration across teams.

Collaboration with finance teams was also seen as critical in the development of CBP.

\subsubsection{Use of technology}

Most PDMs are said to now be digitalized using Mobenzi software. This has the capability to speed up the process, but could tend to lead to a greater reliance on quantitative data at the expense of qualitative. Digital registration systems such as Last Mile Mobile Solutions (LMMS) have also been used in some emergencies, and Oxfam is currently exploring the use of Red Rose software that attempts to address some of the drawbacks of LMMS and enables the provision of e-vouchers. The use of new technology also means that it will become easier to track what people spend money on, even if they are in transit and do not remain in the same location. 


\section{INFORMATION FROM OTHER AGENCIES}

Given the PHP team's ambition to develop global capacity for improving community engagement in humanitarian response, it is important to look critically at the way first-phase emergency responses are implemented.

Some key informants expressed the concern that distributions in kind set up a dynamic with communities that undermined the development of a more equal relationship with communities; one that could potentially strengthen community capacity rather than encourage dependency.

It could be argued that even the provision of cash or vouchers perpetuates the benefactor/beneficiary relationship. However, Myanmar identified that one of the benefits of the use of vouchers was the changed attitude by staff and others towards community members, who became 'consumers' rather than 'beneficiaries'.

Two key informants suggested that it might be possible to use cash-based approaches as incentives for behaviour change by offering discounts, cashback or prizes following the purchase of certain items that might have

'We are trying to build trust but we are just giving out stuff - this creates an expectation and dynamic with communities.'

- PHP Advisor

'When you do vouchers your whole mind set changes for the good - it helps to change your relationship with the people you are working with.'

- Oxfam PM an impact on public health, such as soap or water filters. Previous reviews have, however, noted a resistance to using cash as an incentive to attend training (MartinSimpson 2015) as it might undermine sustainability and sets a dangerous precedent for any social or educational programmes. 


\section{GAPS IN REVIEW AND FURTHER QUESTIONS}

This review has sought to understand the current state of play in Oxfam NFI interventions, but there are several gaps in it. Very little information was available on targeting of NFI interventions, as most provision in the early phases of an acute emergency appears to cover all affected households. It was also not possible in the time available to interview any partner organizations or to speak with affected communities (although the feedback in PDMs was reviewed).

Key informants were predominantly from the WASH sector, although the review did not seek to focus only on WASH-related NFIs.

There are also a variety of issues that were not within the scope of the review's terms of reference, including cross-sector collaboration, meeting the needs of the most vulnerable, an indepth assessment of the use of digital technology, the role of donors, and the pre-positioning of stocks.

It would also be useful to explore the differences in expectations and responses in middle income and low income countries.

There is a need to interview more key informants at sector coordination level, in both the Shelter and WASH sectors, as there is limited information on how coordination of NFIs could be improved. A better appreciation of the issues from the Logistics perspective is required to identify how to better support NFI provision.

While several agencies were contacted, there was only time to gain a broad understanding of the NFI issues affecting the WASH sector as a whole, and how these are currently being addressed outside Oxfam. Some key follow-on questions have been listed in the appendix.

\section{FURTHER QUESTIONS}

- Further investigation into the provision of NFIs and the modalities for doing so is also needed to identify how coordination, targeting and cross sector collaboration can all be improved as well as to explore the following questions:

a. Is overall global proportional humanitarian spend on NFIs increasing or is this just the perception of key informants?

b. What opportunities are there for interagency collaboration on improving the approach to ensuring access to NFIs?

c. How can the evidence base for the distribution of hygiene kits and the use of alternative modalities be developed?

d. How can coordination of the provision of NFIs and/or alternatives be improved? (How should/does Oxfam/ other WASH NGOs coordinate with the Shelter sector on this?)

e. What policy do donors have on funding and stockpiling NFIs or alternatives?

f. How are NFls targeted in Oxfam and other organisations and does targeting make sense in contexts where it will be redistributed anyway? 
g. Can/should cash (or market based approaches) be used as an incentive for behaviour change and how?

h. How can epidemiological data be better used to rationalise NFI interventions? (The table in the appendix attempts to consider the different factors involved in deciding if NFIs are necessary)

i. What additional guidance and support is required to support field staff?

- Where more detailed pre crisis analysis is possible, this information needs to be presented in a form that is more accessible for field staff. Exploring ways to simplify market assessments to make them more feasible in an acute emergency response will also be important and collaboration with other agencies on this is likely to be critical.

- More research is needed to explore how market based approaches such as the use of a partial subsidy rather than a full subsidy (e.g. market offers or discounts such as buy one get one free) can be used to influence consumer behaviour in emergency contexts.

- Further discussions with the Shelter Cluster on the coordination of NFI's and how this can be improved are needed.

- Discussions are also needed with donors who have pre-positioned stocks to ensure that the offer of these does not undermine the use of market based approaches. 


\section{RECOMMENDATIONS}

The following recommendations are based on the limited investigation undertaken within Oxfam and will need to be refined and developed following further discussion and debate with other humanitarian practitioners:

\subsection{OXFAM INTERNAL RECOMMENDATIONS}

\subsubsection{General}

- A standard approach to enabling access to NFIs should be resisted - this is the current state of play in Oxfam, with the ordering of hygiene kits seen as a key first step in every current response. Hygiene items may not be required and most items are probably not 'life saving' in many if not most situations. The need for hygiene items and response objectives in each specific context should be clearly stated, and the argument for not using cash must be clearly documented.

- Needs assessments should identify what people are using already (e.g. home-made soap, local water containers) and consider the likely epidemiological risks and feasibility of current practice, before considering NFI provision as a useful response. It may not always be necessary to provide NFIs.

- It may not be possible (or necessary) in an acute situation to carry out and document an indepth assessment of all NFI needs. If preparedness data (e.g. PCMA or Framework agreements with suppliers) are available for a particular location, this can help to inform the immediate response, but monitoring will need to become more sensitive and pragmatic.

- Investigating the use of multi-purpose cash grants is to be encouraged wherever feasible as an early response, as despite concerns, there is no evidence yet that people will deprioritize hygiene - and additionally, no evidence of the impact of most NFIs on public health. This modality is more likely to contribute to improving dignity than the in-kind provision of hygiene items, and can be combined with the use of vouchers. However, differential impacts need to be closely monitored to ensure that women are still able to manage their menstruation adequately and that hygiene needs are met for different family members.

- It is possible that limited in-kind distributions will continue to be necessary in some contexts and for some items only (e.g. household water treatment or clean water containers) where public health risks are high, such as disease outbreaks or where markets are not functioning.

- While country programmes are expected to develop the terms of reference for evaluations and to identify the key issues for the focus of the evaluation, the current spend on NFIs and the lack of research on the use of cash and multi-purpose grants to achieve WASH goals - warrants a more systematic inclusion in all RTEs and evaluations.

\subsubsection{In-kind distributions}

- Contingency planning for in-kind WASH-related distributions needs to involve the PHP team, Logistics, and Senior Management at global, regional and country level.

- Where hygiene items are judged to be likely to have a public health impact or where assessment shows they will contribute to people's sense of dignity and where in-kind distribution is assessed to be the best ${ }^{6}$ alternative, the provision of a basic hygiene kit only is recommended - rather than a kit that seeks to meet every identified need. This could not 
only speed up procurement and distribution, but also allows the possibility for markets to reestablish themselves and prevents programmes from becoming tied into an in-kind distribution-only mode.

- A phased response to the provision of NFIs may work better than the current approach so that priority needs are met initially with a small in-kind distribution (where markets are not functioning) but the $\mathrm{NFI}$ response can evolve as the context evolves, if hygiene items continue to be required.

\subsubsection{Process issues for in-kind distributions}

- The recruitment of a distribution manager and distribution teams should be given high priority in a large-scale emergency where distributions in kind are expected. It will probably be necessary for WASH staff in the field and at HQ to continue to lobby for this to be incorporated into budgets and planning. Ensuring a successful and effective in-kind distribution of WASH items will continue to be the responsibility of both Logistics and PHP and it may be necessary to map out more clearly the respective roles and responsibilities of each, and ensure that programme managers encourage collaborative working.

- Experience seems to have shown that people are usually not listening to the information provided at the time of a large-scale distribution, and this strategy must change. For example, Oxfam could ensure smaller distributions and adequate staff to listen and discuss with people. This could be done through innovative approaches such as dialogue platforms and women or children's corners used in Nepal, or by simply considering carefully what information is critical during the distribution (e.g. what will enable people to navigate the distribution system more effectively), and what information is better emphasized later through household visits or other PHP activities.

- Procedures for PDM also need to be reviewed, and more detailed guidance provided to field staff. There is a need for greater involvement of PHP in the design and analysis of monitoring studies, and the PDM process needs to be incorporated into programme plans. The use of more innovative methods - drawing on qualitative data and not just quantitative data - should also be explored. Questions relating to market access could be usefully included in PDMs.

- A multi-sector approach to the provision of in-kind NFIs (as with the provision of multipurpose grants) probably makes for a better experience for recipient families and communities, rather than simply focusing on specific hygiene or protection needs. It is important that this is seen as a programme rather than a sector issue. Community level inkind distributions such as sanitation tools or safety kits can be provided by sector staff. But it makes more sense for dignity kits comprising MHM items and underwear to be provided by distribution teams as part of, or at the same time as, other household-level provision.

- More information is needed on the development of a 'distribution kit' to support the setup and management of in-kind distributions.

\subsubsection{Market-based approaches (MBAs)}

- Ideally all responses (including in-kind distributions) should incorporate market assessments, and the decision about which tools can best meet the needs of the population should only be made following such an assessment. In recurrent emergencies, a pre-crisis assessment and other preparedness activities could help to reduce the time needed for this.

- Where more detailed pre-crisis analysis is possible, this information needs to be presented in a form that is more accessible for field staff. Exploring ways to simplify market assessments to make them more feasible in an acute emergency response will also be important, and collaboration with other agencies on this is likely to be critical. 
- More research is needed to explore how MBAs, such as the use of a partial subsidy rather than a full subsidy (e.g. market offers or discounts such as 'buy one get one free') can be used to influence consumer behaviour in emergency contexts.

- Further discussions are needed with the Shelter Cluster on the coordination of NFIs and how this can be improved.

- Discussions are also needed with donors who have pre-positioned stocks, to ensure that the offer of these does not undermine the use of MBAs. 


\section{APPENDIX}

\subsection{TERMS OF REFERENCE}

\section{Desktop review of NFI distributions in humanitarian response}

\section{Background}

Humanitarian response programmes frequently include the distribution of NFIs to meet some of the basic and most immediate needs of communities affected by emergencies. Anecdotal evidence suggests that the number and diversity of items and kits (hygiene kits, menstrual hygiene kits, mother and baby kits, dignity kits, etc.) distributed in recent years may be increasing. In Oxfam, reporting tends to focus on the numbers of kits distributed rather than a narrative about their usefulness to the end users.

The objective of this review is to get a better understanding of the extent and effectiveness of $\mathrm{NFI}$ distributions in Oxfam programmes. The findings of the review will be used to make recommendations for programme policy and guidance to maximize the impact of NFI distributions or alternatives in future responses.

This is primarily an internal review but the consultant will explore the potential for involving other agencies through sharing relevant documents or participating in interviews where possible.

Ten days (to be reviewed in relation to the level of engagement of other agencies) are allocated for this consultancy to be carried out between mid-February and the end of March.

\section{Key activities}

1. Review programme data and reports on OPAL for 2013-2016 that include information on $\mathrm{NFI}$ spend and activities in humanitarian responses during this period.

2. Conduct a literature review of key documents from Oxfam (RTEs, programme reports, MEAL documents and learning reviews) and other humanitarian agencies for information on the following:

- How were needs assessed prior to the NFI distribution?

- How was targeting carried out?

- Was market access and the distribution of cash or vouchers considered as an alternative to goods in kind?

- At what stage in the response was the distribution implemented?

- What was the content of the materials distributed and where were these procured?

- Who was involved in implementing the distribution, e.g. distribution teams, technical staff (PHPs, PHEs, EFSVLs, Logisticians, ICT staff), partner organizations?

- Was post-distribution monitoring carried out and if so, were the findings reported and/or used to modify the programme where appropriate?

- How were the outputs and outcomes of the distributions reported and communicated? 
3. Interview a selection of key stakeholders in Oxfam (e.g. advisers, HSPs, programme staff) and other agencies to further explore the findings and develop recommendations for future programme responses.

\section{Outputs}

A report (maximum 12 pages) which summarizes the findings of the desktop review and key informant interviews. It should include recommendations derived from these findings for NFI distributions or alternatives in future programmes.

\section{Key skills and competencies}

1. Degree-level qualification in public or environmental health or an equivalent discipline.

2. Considerable field experience of working in emergency contexts with displaced and refugee populations and host communities.

3. Experience of conducting literature reviews and key informant interviews and using the findings to make clear programme recommendations.

4. Good overview of the humanitarian agencies who implement NFI distributions in emergencies and the networks through which they can be contacted.

5. Ability to work to deadlines and with minimal support.

6. Good analytical skills and the ability to extract key trends from diverse sources.

7. Excellent communication skills. 


\subsection{POTENTIAL FACTORS TO CONSIDER WHEN ASSESSING THE NEED FOR HYGIENE NFIS}

\begin{tabular}{|c|c|c|c|c|c|}
\hline Effect & $\begin{array}{l}\text { Complex } \\
\text { Emergencies }\end{array}$ & Earthquakes & $\begin{array}{l}\text { High } \\
\text { winds }\end{array}$ & Floods & Flash floods \\
\hline Deaths & Many & Many & Few & Few & Many \\
\hline $\begin{array}{l}\text { Risk of } \\
\text { communicable } \\
\text { disease }\end{array}$ & High & $\begin{array}{l}\text { Varies } \\
\text { according to } \\
\text { displacement/ } \\
\text { living } \\
\text { conditions }\end{array}$ & Small & $\begin{array}{l}\text { Varies } \\
\text { according to } \\
\text { displacement/ } \\
\text { living } \\
\text { conditions }\end{array}$ & $\begin{array}{l}\text { Varies } \\
\text { according to } \\
\text { displacement/ } \\
\text { living } \\
\text { conditions }\end{array}$ \\
\hline Food scarcity & Common & Rare & Rare & Varies & Common \\
\hline $\begin{array}{l}\text { Population } \\
\text { displacement }\end{array}$ & Common & Rare & Rare & Varies & Common \\
\hline \multicolumn{6}{|c|}{$\begin{array}{l}\text { How to decide if there is an immediate need for NFIs (refer to above table to help inform decision } \\
\text { making) }\end{array}$} \\
\hline $\begin{array}{l}\text { What warning did } \\
\text { people have - } \\
\text { were they able to } \\
\text { prepare? }\end{array}$ & Varies & Low & High & High & Low \\
\hline \multicolumn{6}{|l|}{$\begin{array}{l}\text { Have they arrived } \\
\text { with or without } \\
\text { belongings? }\end{array}$} \\
\hline \multicolumn{6}{|l|}{$\begin{array}{l}\text { How long are they } \\
\text { likely to stay? }\end{array}$} \\
\hline \multicolumn{6}{|l|}{$\begin{array}{l}\text { What is their } \\
\text { existing access to } \\
\text { critical NFIs (soap, } \\
\text { water containers } \\
\text { etc.)? }\end{array}$} \\
\hline $\begin{array}{l}\text { What does the } \\
\text { public health data } \\
\text { indicate? }\end{array}$ & & & & & \\
\hline
\end{tabular}

Source: Adapted from Sphere Standards 2011 p.293 


\subsection{CONTACT LIST FOR REVIEW}

\begin{tabular}{|c|c|c|}
\hline & Name & Position \\
\hline 1. & Foyeke Tolani & Oxfam PHP Advisor \\
\hline 2. & Lucy Knight & Oxfam PHP Advisor \\
\hline 3. & Sophie Caussanel & Oxfam PHP Advisor \\
\hline 4. & Eva Niederberger & Oxfam PHP Advisor/HSP \\
\hline 5. & Michelle Farrington & HSP PHP \\
\hline 6. & Mimi Asibel & HSP PHP \\
\hline 7. & Zulfi Ali & WASH Co-ordinator \\
\hline 8. & Dr Hasnain & PM Pakistan (ex PHP) \\
\hline 9. & John Kerr & HSP Logistics \\
\hline 10. & Alia Shams & PHP TL Syria \\
\hline 11. & Pilar Duch & Oxfam Protection Advisor \\
\hline 12. & Katie Whitehouse & Oxfam Urban WASH and Markets \\
\hline 13. & Vivien Walden & Oxfam MEAL TL \\
\hline 14. & Vincent Koch & Niger PR (and Europe) \\
\hline 15. & Rakesh Mohan & Oxfam Area Manager Myanmar \\
\hline 16. & $\begin{array}{l}\text { Yasir Syed } \\
\text { Jorge Roman }\end{array}$ & IMC \\
\hline 17. & Alesh Brown & World Vision \\
\hline 18. & Robert Cruickshank & CAFOD \\
\hline 19. & Claire Grisaffi & $\mathrm{BRC}$ \\
\hline 20. & Peninah Mathenge & IRC \\
\hline
\end{tabular}




\subsection{REFERENCES}

Brady, C., and Creti, P., (2011). Shop Vouchers for Hygiene Kits in Port-au-Prince, Haiti (CaLP Case Study).

Brady, C. and Van Borek, N., (2011), Non Food Item Voucher Fairs in Walikale Territory, North Kivu, DRC: A UNICEF and Solidarités International programme (CaLP Case Study).

Global WASH Cluster Markets Technical Working Group (2016). Cash and Markets In The WASH Sector: A global WASH Cluster position paper.

IRC (2016). Cost Efficiency Analysis: Non-Food Items Vs. Cash Transfers.

IRC (2015). Cost Efficiency Analysis: Unconditional Cash Transfer Programs.

Julliard, H. and Opu, M. (2014). Scoping Study: Emergency Cash Transfer Programming in the WaSH and Shelter Sectors (CaLP).

Maertens, A. Whitehouse, K. and Klassen, M. (2017). Applying Behavioural Economics to Market Systems in Household Water Treatment Products: Implications for humanitarian interventions and development programming (draft).

Martin-Simpson (2015). Scoping Study: The Use Of Cash Transfer Programming And Marketbased Approaches To Achieve Public Health Promotion Outcomes In Humanitarian Response.

Matthews et al (2015). Pre-Crisis Market Mapping and Analysis: The water market system in the context of severe flooding Badin, Ghotki and Sanghar Districts, Sindh Province, Pakistan.

Ngala, P. and Whitehouse, K. (2016). Domestic water supply, sanitation and hygiene products Harare, Zimbabwe PCMA.

Olivier de Sardan, J. (2013). Les transferts monétaires au Niger : la manne et les soupçons, Synthèse des recherches menées par le LASDEL.

Oxfam (2012). MEAL Minimum Standards in Oxfam Humanitarian Programmes.

Oxfam (2016). Roles and responsibilities for MEAL and Knowledge Management in a first phase emergency.

Oxfam (2016). RTE: Oxfam's Response to El Niño in Papua New Guinea 2015-2016.

Oxfam (2015). RTE: Nepal Earthquake Response.

Oxfam (2016). Nepal Earthquake WASH Response: Learning Review of Community Engagement, MHM and Capacity Building.

Oxfam (2016). RTE: Oxfam's Response to Tropical Cyclone Winston, Fiji.

Oxfam (2014). RTE: Typhoon Haiyan Response in the Philippines, January 2014.

Oxfam (2015). Oxfam multi-sector rapid needs assessment of refugees/migrants in Kos Island, Greece.

Oxfam (no date). Response and Resilience Team: Distribution Manager Job Description.

Oxfam Myanmar (2016). Hygiene Items Market assessment IDP Camps, Sittwe Township, Rakhine State, Myanmar. 
Oxfam Myanmar (2016). Operational Process Guide for Shop Vouchers for NFIs - Hygiene Kit.

Oxfam (2016). Irish Aid Stock Request for Chad Basin Crisis Response in Nigeria.

Oxfam (2016). PCMA: Domestic Water and Latrine Market Systems Jakarta, Indonesia.

Sagan, S. (2014). Hygiene Kit Market Assessment Report (PowerPoint).

Wildman et al (2016). PCMA for Wash NFI and sanitation hardware market systems in Fazlupur and Fulchari unions, Gaibandha district, Bangladesh: Informing emergency response and preparedness to extreme flood events.

Whitehouse, K. (Feb 2017). Conditional WASH voucher programmes in Zimbabwe: The critical importance of nuances in programme design to deliver intended outcomes (Oxfam internal document)

Yates, T. Allen, J. Leandre Joseph, M. and Lantagne, D. (2017). WASH interventions in disease outbreak response: Humanitarian Evidence Programme.

Yussuf, M. (2016). Pre-Crisis Market Mapping and Analysis using the Rapid Assessment for Markets (RAM) Toolkit.

Mogadishu, Somalia; Internal Displacement; 2015.

Various sitreps from LCB, Syria, Haiti, Europe responses.

Various PDMs from Fiji, South Sudan response, Chad, Pakistan.

Various response strategies from Fiji, LCB, Yemen, Europe, Sierra Leone.

Distribution plans and flowcharts from Nepal, Nigeria and Sierra Leone. 


\subsection{IDENTIFIED ISSUES IN RELATION TO DIFFERENT NON-FOOD ITEM DISTRIBUTION MODALITIES}

\begin{tabular}{|c|c|c|c|c|}
\hline & In kind & $\begin{array}{l}\text { Commodity } \\
\text { Voucher }\end{array}$ & $\begin{array}{l}\text { Value } \\
\text { Voucher }\end{array}$ & Cash \\
\hline \multirow[t]{3}{*}{ Feasibility } & $\begin{array}{l}\text { Use when markets not functioning, but if } \\
\text { lead time for procurement is long, markets } \\
\text { may be working again }\end{array}$ & \multicolumn{3}{|c|}{$\begin{array}{l}\text { Markets need to be functioning and need a rapid market assessment to understand: } \\
\text { How quickly can the market meet the increased demand or adapt to demand? }\end{array}$} \\
\hline & $\begin{array}{l}\text { People often walking long distances to } \\
\text { distribution sites }\end{array}$ & \multicolumn{3}{|c|}{ Are people willing to travel/walk further than we think to access markets? } \\
\hline & $\begin{array}{l}\text { Should consider impact on markets even } \\
\text { when doing in-kind distribution }\end{array}$ & $\begin{array}{l}\text { Are there times when this is } \\
\text { preferred } \mathrm{PH} \text { option e.g. cholera } \\
\text { outbreak }\end{array}$ & \multicolumn{2}{|c|}{ Will people prioritize items that have public health impact? } \\
\hline Quality of items & Quality overseen by Logistics & \multicolumn{2}{|c|}{$\begin{array}{l}\text { Consumer determines quality by shopping around but might not be } \\
\text { possible if only limited suppliers available }\end{array}$} & \\
\hline Impact on health & $\begin{array}{l}\text { What evidence exists for PH impact of } \\
\text { hygiene kits? } \\
\text { (paper on distribution of soap in cholera } \\
\text { response) } \\
\text { Do people always use them? 'Save new } \\
\text { items for dowry' } \\
\text { Small percentages not using from PDMs } \\
\text { Not consistently providing LLINs - are we } \\
\text { asking? }\end{array}$ & $\begin{array}{l}\text { What evidence exists for } \mathrm{PH} \\
\text { impact of hygiene items? } \\
\text { Maybe for soap and clean water } \\
\text { containers? }\end{array}$ & $\begin{array}{l}\text { What evidence that better or } \\
\text { worse than cash or value } \\
\text { vouchers? }\end{array}$ & $\begin{array}{l}\text { What evidence is there that people will } \\
\text { or will not prioritize hygiene items? } \\
\text { 'Early days of cash worried that would } \\
\text { buy alcohol and cigarettes' }\end{array}$ \\
\hline Speed and timing & $\begin{array}{l}\text { Can be rapid but only if contingency or } \\
\text { framework agreement with suppliers } \\
\text { already available. Easier if all kits are the } \\
\text { same using only key suppliers }\end{array}$ & \multicolumn{2}{|c|}{$\begin{array}{l}\text { Can it be set up quickly enough in first phase? Does it matter if takes } \\
\text { more time? What impact would delay have on public health? } \\
\text { Haiti pilot took } 3 \text { months to initiate but no dedicated staffing }\end{array}$} & $\begin{array}{l}\text { Examples of first phase response from } \\
\text { EFSVL but small(er) numbers } \\
\text { targeted? }\end{array}$ \\
\hline
\end{tabular}




\begin{tabular}{|c|c|c|c|c|}
\hline & & \multicolumn{2}{|c|}{$\begin{array}{l}\text { Seen by logistics to be potentially burdensome to use multiple small } \\
\text { suppliers }\end{array}$} & \\
\hline & $\begin{array}{l}\text { Should there be a cut-off point after which } \\
\text { distributions should not be carried out - or } \\
\text { when appropriateness should be } \\
\text { reviewed? }\end{array}$ & \multicolumn{2}{|c|}{$\begin{array}{l}\text { Is a time limit for spending these necessary? } \\
\text { Need to consider when shops are open }\end{array}$} & \\
\hline \multirow[t]{3}{*}{ Choice and dignity } & $\begin{array}{l}\text { Even if do a needs assessment, people will } \\
\text { have different and varying needs between } \\
\text { areas and within } \mathrm{HH}\end{array}$ & $\begin{array}{l}\text { No choice of items and limited } \\
\text { choice of suppliers }\end{array}$ & $\begin{array}{l}\text { Allows limited choice of items and } \\
\text { suppliers so can only shop around } \\
\text { within limits }\end{array}$ & $\begin{array}{l}\text { Can shop around for best value } \\
\text { Allows free choice of purchases so may } \\
\text { not prioritize public health. }\end{array}$ \\
\hline & $\begin{array}{l}\text { Have to walk to then wait at distribution site } \\
\text { - often go early as worried they will miss } \\
\text { out } \\
\text { People exposed to elements during } \\
\text { distribution, difficult for most vulnerable, } \\
\text { people feel they are recipients of charity }\end{array}$ & \multicolumn{3}{|c|}{$\begin{array}{l}\text { People don't have to wait in line for hours or transport large kits back home in one go } \\
\text { Feels more like an entitlement }\end{array}$} \\
\hline & $\begin{array}{l}\text { May be an additional burden when in } \\
\text { transit but sometimes more appropriate for } \\
\text { new arrivals (e.g. Nigeria) }\end{array}$ & & & \\
\hline \multirow[t]{2}{*}{ Targeting } & $\begin{array}{l}\text { Can cause/exacerbate community tensions } \\
\text { if targeted rather than blanket }\end{array}$ & \multicolumn{3}{|c|}{ Possibly easier to target as more discreet } \\
\hline & \multicolumn{4}{|c|}{$\begin{array}{l}\text { Need to consider errors of inclusion and exclusion when targeting } \\
\text { Even if target there will often be some degree of redistribution in tight-knit communities. What evidence do we have for this? }\end{array}$} \\
\hline \multirow[t]{3}{*}{ Security } & $\begin{array}{l}\text { May attract rioting or attacks on distribution } \\
\text { sites }\end{array}$ & \multicolumn{3}{|c|}{ Rebel groups may target markets (but people probably using them anyway) } \\
\hline & & \multicolumn{2}{|c|}{$\begin{array}{l}\text { Improved security compared to distributions - may be preferred to } \\
\text { cash } \\
\text { E-vouchers possible }\end{array}$} & $\begin{array}{l}\text { May be security risks for staff and } \\
\text { recipients but mitigated by using newer } \\
\text { systems such as Red Rose? }\end{array}$ \\
\hline & Risk of fraud and corruption: looting & \multicolumn{2}{|l|}{ Risk of fraud } & Risk of fraud and corruption \\
\hline Resilience & Can undermine local market setting up a & Benefits for selected traders but & $\begin{array}{l}\text { Benefits for local market but } \\
\text { usually limited traders - might be }\end{array}$ & Benefits for local economy \\
\hline
\end{tabular}




\begin{tabular}{|c|c|c|c|c|}
\hline & parallel market for limited time & limits number of traders involved & bigger outlets & \\
\hline & \multicolumn{4}{|c|}{$\begin{array}{l}\text { Do all modalities have potential to cause intra-community or household conflict and people may seek to control the resource - not a given that it will be shared } \\
\text { even in the HH (e.g. PDM from South Sudan reporting that female head of household forbade anyone from using Lifesaver filter when she was away.) But } \\
\text { negotiating such issues is legitimate area of focus for PHP. }\end{array}$} \\
\hline & \multicolumn{2}{|c|}{$\begin{array}{l}\text { People may sell or exchange items or keep as new for alternative purpose e.g. } \\
\text { dowry }\end{array}$} & $\begin{array}{l}\text { People can decide what they need } \\
\text { and quantities of pre-defined } \\
\text { items }\end{array}$ & $\begin{array}{l}\text { People prioritize what they need - no } \\
\text { wastage }\end{array}$ \\
\hline \multirow[t]{5}{*}{$\begin{array}{l}\text { Programme } \\
\text { issues }\end{array}$} & $\begin{array}{l}\text { Takes up significant amount of PHP } \\
\text { programme time in big emergency } \\
\text { especially - limits time for important PHP } \\
\text { activities with communities }\end{array}$ & \multicolumn{2}{|c|}{$\begin{array}{l}\text { Also takes time to organize and monitor but less than distributions } \\
\text { once set up? }\end{array}$} & Time required to manage and monitor \\
\hline & $\begin{array}{l}\text { Can be seen as paternalistic and } \\
\text { perpetuates unequal dynamic between } \\
\text { PHP staff and community }\end{array}$ & \multicolumn{3}{|c|}{ Provision of vouchers and cash might also be seen as paternalistic - unless carried out by separate teams? } \\
\hline & $\begin{array}{l}\text { Is a distribution always necessary as } \\
\text { default position? }\end{array}$ & \multicolumn{3}{|c|}{$\begin{array}{l}\text { Vouchers and cash for hygiene items may also not always be necessary - need to explore people's own coping } \\
\text { mechanisms more } \\
\text { Consider items that people prioritize to take with them as in the case of Bangladesh floods - said they had } \\
\text { materials for MHM and took water containers with them. (this is what needs assessment should identify) } \\
\text { Maybe MPGs are best option? The role of the PHP is then to determine if and where there might be gaps }\end{array}$} \\
\hline & $\begin{array}{l}\text { Need to review distribution approach and } \\
\text { information provision as often recipients } \\
\text { not listening and it becomes rushed and } \\
\text { mechanistic - not real communication }\end{array}$ & \multicolumn{3}{|c|}{$\begin{array}{l}\text { What is potential to use partly as incentive for behaviour change? } \\
\text { E.g. money back or discounts on purchase of specific items like soap } \\
\text { Cash for training seen as unethical/counterproductive }\end{array}$} \\
\hline & $\begin{array}{l}\text { Emergency response reduced to provision } \\
\text { of kits of multiple kinds: } \\
\text { Water, hygiene, dignity, safety, kitchen, } \\
\text { shelter etc. }\end{array}$ & \multicolumn{3}{|c|}{ MPGs allow people to make decisions for themselves about what they need } \\
\hline $\begin{array}{l}\text { Needs/Market } \\
\text { Assessment }\end{array}$ & Not often recorded & \multicolumn{3}{|c|}{ MA not often done - when done does not lead to intervention } \\
\hline Integration with & & & & Could combine cash distribution with \\
\hline
\end{tabular}




\begin{tabular}{|l|l|l|l|l|}
\hline EFSVL & & & \multicolumn{1}{|l|}{$\begin{array}{l}\text { EFSVL in first phase but they will often } \\
\text { target } \\
\text { Would this matter? Target initially then } \\
\text { reassess? }\end{array}$} \\
\hline $\begin{array}{l}\text { Logistics and } \\
\text { finance }\end{array}$ & $\begin{array}{l}\text { Needs collaboration for all distribution modalities } \\
\text { Define roles and responsibilities in relation to each modality - key lesson from Haiti voucher pilot }\end{array}$ & \\
\hline Dedicated staff & $\begin{array}{l}\text { Need for separate distribution teams? } \\
\text { Especially in large-scale emergencies }\end{array}$ & Need for key person in PHP (and maybe logs and finance) to focus on CBI if appropriate? \\
\hline Monitoring & $\begin{array}{l}\text { PDMs often self-serving } \\
\text { Do not pick up on some of key issues (see } \\
\text { Bangladesh PCMA) } \\
\text { Need better guidance so more } \\
\text { standardized. } \\
\text { Review current questions as people only } \\
\text { agree } \\
\text { Include questions about markets? }\end{array}$ & $\begin{array}{l}\text { Monitor WASH items that are bought } \\
\text { with cash (see NRC report) }\end{array}$ \\
\hline & $\begin{array}{l}\text { Some evidence of adaptation in kits and } \\
\text { contents but limited. }\end{array}$ & $\begin{array}{l}\text { PDMs predominantly quantitative and data } \\
\text { not triangulated. Also take time and } \\
\text { resources and do not appear to often } \\
\text { deliver useful results. }\end{array}$ & & \\
\hline
\end{tabular}




\subsection{OVERVIEW OF OXFAM DISTRIBUTIONS}

\begin{tabular}{|c|c|c|c|c|c|c|c|c|}
\hline Distribution & $\begin{array}{l}\text { South Sudan } \\
2015 \\
\text { Cholera } \\
\text { response and } \\
\text { EP\&R } 2016\end{array}$ & $\begin{array}{l}\text { Pakistan } \\
\text { 2011-12 } \\
\text { and current }\end{array}$ & Jordan & Syria & Lebanon & Iraq & $\begin{array}{l}\text { Fiji - Cyclone } \\
\text { Winston } 2016\end{array}$ & Yemen \\
\hline $\begin{array}{l}\text { Needs } \\
\text { assessment }\end{array}$ & $\begin{array}{l}\text { Yes - sometimes } \\
\text { distribute at same } \\
\text { time when } \\
\text { access difficult }\end{array}$ & $\begin{array}{l}\text { Yes - used matrix } \\
\text { ranking }\end{array}$ & Yes & Yes & Yes & Yes & Yes & Yes \\
\hline $\begin{array}{l}\text { Market } \\
\text { Assessment } \\
\text { /CBI? }\end{array}$ & & $\begin{array}{l}\text { Use Cash for } \\
\text { Work (CFW) in } \\
\text { WASH } \\
\text { No - focus on } \\
\text { EFSVL only }\end{array}$ & $\begin{array}{l}\text { Hygiene vouchers } \\
\text { Water vouchers }\end{array}$ & $\begin{array}{l}\text { Intend to do an } \\
\text { EMMA - but } \\
\text { difficult to get } \\
\text { approval - } \\
\text { managed by } \\
\text { EFSVL through } \\
\text { private company }\end{array}$ & $\begin{array}{l}\text { Hygiene } \\
\text { vouchers }\end{array}$ & Not for WASH & $\begin{array}{l}\text { Yes: plans to } \\
\text { provide } \\
\text { vouchers for } \\
\text { sanitation and } \\
\text { hygiene items } \\
\text { as refill (but not } \\
\text { implemented > } \\
\text { turnover, } \\
\text { partner led } \\
\text { implementation } \\
\ldots \text {..) }\end{array}$ & $\begin{array}{l}\text { CASH/voucher for } \\
\text { shelter and EFSVL }\end{array}$ \\
\hline Targeting & $\begin{array}{l}\text { Most vulnerable } \\
\text { communities/ } \\
\text { villages }\end{array}$ & Blanket usually & $\begin{array}{l}\text { Host community - } \\
\text { targeted }\end{array}$ & $\begin{array}{l}\text { Blanket in IDP } \\
\text { centres and some } \\
\text { key villages/areas }\end{array}$ & $\begin{array}{l}\text { Blanket: Syrian } \\
\text { refugees in ITS } \\
\text { (Bekaa valley) }\end{array}$ & & $\begin{array}{l}\text { Blanket } \\
\text { approach }\end{array}$ & $\begin{array}{l}\text { IDP targeting } \\
\text { initially }\end{array}$ \\
\hline Timing & $\begin{array}{l}\text { Different in } \\
\text { different areas - } \\
\text { access often } \\
\text { delays }\end{array}$ & & $\begin{array}{l}\text { Ongoing: } \\
\text { newcomers and } \\
\text { refill }\end{array}$ & & Every 3 months & $\begin{array}{l}2-3 \text { weeks to } \\
\text { procure (restricted } \\
\text { tender) but longer if } \\
\text { don't know market }\end{array}$ & & $\begin{array}{l}\text { Different in different } \\
\text { areas }\end{array}$ \\
\hline Type of kit & $\begin{array}{l}\text { Hygiene } \\
\text { Solar lamps }\end{array}$ & $\begin{array}{l}\text { Hygiene kit, } \\
\text { School kit, СTC }\end{array}$ & $\begin{array}{l}\text { Family hygiene kit - } \\
\text { new arrivals and }\end{array}$ & $\begin{array}{l}\text { Family hygiene } \\
\text { kits }\end{array}$ & $\begin{array}{l}\text { Family hygiene } \\
\text { kits }\end{array}$ & Hygiene kit & & $\begin{array}{l}\text { Basic plus } \\
\text { menstrual hygiene }\end{array}$ \\
\hline
\end{tabular}




\begin{tabular}{|c|c|c|c|c|c|c|c|}
\hline & & Latrine cleaning & $\begin{array}{l}\text { consumables } \\
\text { Baby hygiene kit }\end{array}$ & $\begin{array}{l}\text { Children's } \\
\text { hygiene kits } \\
\text { Latrine kit } \\
\text { One-off } \\
\text { distribution of } \\
\text { nappies in Aleppo } \\
\text { Mini-hygiene kit in } \\
\text { Aleppo: soap } \\
\text { bars, washing } \\
\text { powder, shampoo } \\
\text { and sanitary pads }\end{array}$ & & & $\begin{array}{l}\text { management } \\
\text { (MHM) }\end{array}$ \\
\hline Contents & $\begin{array}{l}\text { Bucket with tap, } \\
\text { bucket without } \\
\text { tap, ORS, PUR } \\
\text { (aqua tab), } \\
\text { ebriks, poop } \\
\text { scoop, soap, } \\
\text { basin, Afripad, } \\
\text { and under wear, } \\
\text { solar lamps (For } \\
\text { lactating women) } \\
\text { OFDA: 20L, one } \\
\text { 10L, and two } 5 \mathrm{~L} \\
\text { jerry cans, two } \\
\text { underpants, two } \\
\text { reusable sanitary } \\
\text { pads, one poop } \\
\text { scoop, one water } \\
\text { filter and } 2 \text { bars } \\
\text { of soap (800g). } \\
\text { Life-saver cubes }\end{array}$ & $\begin{array}{l}\text { Soap } \\
\text { Phenyl } \\
\text { Iron bucket } \\
\text { Broom, brush with } \\
\text { short handle and } \\
\text { plastic bucket } \\
\text { (quality to be } \\
\text { ensured in new } \\
\text { kits) } \\
\text { Mop } \\
\text { Mask } \\
\text { Glove } \\
\text { Water cooler } \\
\text { Mosquito net } \\
\text { Bathing and } \\
\text { laundry soaps } \\
\text { Plastic bucket } \\
\text { with lid and jerry } \\
\text { can }\end{array}$ & $\begin{array}{l}\text { Host community }(5 \\
\text { person/HH) } \\
\text { Soap for hand } \\
\text { washing } \\
(250 \mathrm{gr} / \mathrm{p} / \mathrm{m}) \\
\text { Soap powder } \\
(200 \mathrm{gr} / \mathrm{p} / \mathrm{m}) \\
\text { Plastic jerry can } \\
\text { narrow neck (20L) } \\
\text { Safety pins } \\
\text { Toothpaste } \\
\text { (Colgate) (2 adult, } 3 \\
\text { children sizes) } \\
\text { Toothpaste (150ml) } \\
\text { Nail cutter } \\
\\
\text { Informal tented } \\
\text { settlement }(7 \\
\text { person/HH) }\end{array}$ & $\begin{array}{l}\text { Sanitary napkins } \\
\text { Anti-lice shampoo } \\
\text { (targeted) } \\
\text { Blankets } \\
\text { Water bottles } \\
\text { Jerry cans }\end{array}$ & $\begin{array}{l}\text { Shampoo 2L } \\
\text { bottle (1) } \\
\text { Dish cleaning } \\
\text { liquid 2L bottle } \\
\text { (1) } \\
\text { House cleaning } \\
\text { liquid 2L bottle } \\
\text { (1) } \\
\text { Clothes washing } \\
\text { powder 2kg } \\
\text { packs (1) } \\
\text { Toothpaste 2 } \\
\text { big tubes (2) } \\
\text { Toothbrush } 2 \\
\text { big and 2 } \\
\text { medium (4) } \\
\text { Soap 250g } \\
6 \text { sanitary } \\
\text { napkins } 3 \text { packs } \\
\text { each with } 10\end{array}$ & $\begin{array}{l}\text { Jerry cans } \\
\text { Bucket } \\
\text { Basin } \\
\text { Soap } \\
\text { MHM } \\
\text { Underwear (diff } \\
\text { sizes) } \\
\text { Nappies } \\
\text { Detergent } \\
\text { Ibriq } \\
\text { Initial } \\
\text { Jerry can } \\
\text { Solar light } \\
\text { Blanket } \\
\text { Kerosene heater }\end{array}$ & \\
\hline
\end{tabular}




\begin{tabular}{|c|c|c|c|c|c|c|c|c|}
\hline & & $\begin{array}{l}\text { Bath towel } \\
\text { Glasses with } \\
\text { handle (plastic) } \\
\text { Sanitary clothes } \\
\text { and lota (plastic) } \\
\text { Nail cutter } \\
\text { Comb } \\
\text { Sometimes } \\
\text { underwear }\end{array}$ & $\begin{array}{l}\text { Soap for hand } \\
\text { washing } \\
(250 \mathrm{gr} / \mathrm{p} / \mathrm{m}) \\
\text { Soap powder } \\
\text { (200gr/p/m) } \\
\text { Plastic jerry can } \\
\text { narrow neck (20L) } \\
\text { Safety pins } \\
\text { Toothpaste } \\
\text { (Colgate) (2 adult, } 3 \\
\text { children sizes) } \\
\text { Toothpaste (150ml) } \\
\text { Nail cutter } \\
\text { Plastic basin } \\
\text { Baby cover } \\
\text { Soap box } \\
\text { Bucket with lid and } \\
\text { tap (Oxfam bucket) } \\
\text { Aluminium pot for } \\
\text { anal cleansing }\end{array}$ & & $\begin{array}{l}\text { pieces } \\
3 \text { diapers } 2 \\
\text { packs each with } \\
48 \text { pieces } \\
2 \text { hair comb } \\
1 \text { nail cutter }\end{array}$ & & & \\
\hline $\begin{array}{l}\text { Procurement/ } \\
\text { donations from } \\
\text { other e.g. UN }\end{array}$ & $\begin{array}{l}\text { Irish Aid } \\
\text { Sun life }\end{array}$ & & Procured locally & Procured locally & Procured locally & Irish Aid & $\begin{array}{l}\text { Initially Oxfam } \\
\text { Australia } \\
\text { (contingency } \\
\text { stock), UNICEF } \\
\text { Fiji plus local } \\
\text { procurement }\end{array}$ & Procured locally \\
\hline $\begin{array}{l}\text { Who involved } \\
\text { and staffing } \\
\text { needs? }\end{array}$ & $\begin{array}{l}\text { PHP - but one } \\
\text { distribution officer } \\
\text { also - organizes } \\
\text { kits, crowd }\end{array}$ & $\begin{array}{l}\text { Sometimes } \\
\text { distribution } \\
\text { assistants } \\
\text { Had distribution }\end{array}$ & $\begin{array}{l}\text { PHP/EFSVL teams } \\
+ \text { distribution } \\
\text { volunteers }\end{array}$ & $\begin{array}{l}\text { Managed by PHP } \\
\text { or collaboration } \\
\text { with SARC - Logs } \\
\text { procure }\end{array}$ & PHP teams & $\begin{array}{l}\text { PHP teams } \\
\text { Logistics procure } \\
\text { and transport }\end{array}$ & Partner NGO & $\begin{array}{l}\text { PHP teams plus } \\
\text { logistics (not } \\
\text { consistently but } \\
\text { where possible for }\end{array}$ \\
\hline
\end{tabular}




\begin{tabular}{|c|c|c|c|c|c|c|c|}
\hline & $\begin{array}{l}\text { control } \\
\text { Recommendation } \\
\text { that should be } \\
\text { managed by PHP }\end{array}$ & $\begin{array}{l}\text { manager in } 2011 \\
\text { but did not help. } \\
\text { Identification of } \\
\text { beneficiaries, } \\
\text { registration, demo } \\
\text { of kits contents, } \\
\text { distribution of } \\
\text { items, etc. All } \\
\text { done by PHP } \\
\text { team. } \\
\text { Used volunteers } \\
\text { to supplement }\end{array}$ & & $\begin{array}{l}\text { EFSVL managing } \\
\text { proposed EMMA }\end{array}$ & & & security aspects) \\
\hline $\begin{array}{l}\text { Numbers } \\
\text { distributed }\end{array}$ & & & 3019 families & $\begin{array}{l}14450 \text { individual. } \\
\text { previously with } \\
\$ 40 \text {, now: } 9340 \\
\text { individual with } £ 20\end{array}$ & & 2000 families & \\
\hline Value of each kit & & $\$ 25$ & $\begin{array}{l}\$ 21 \text { (\$19.67 - host } \\
\text { community, } 34.45- \\
\text { informal tented } \\
\text { settlements) }\end{array}$ & & $\$ 40$ & & \\
\hline $\begin{array}{l}\text { PDM carried } \\
\text { out? Qualitative } \\
\text { or quantitative }\end{array}$ & $\begin{array}{l}\text { Yes several - } \\
\text { questionnaire } \\
\text { survey mainly - } \\
\text { also observation } \\
\text { Soap sometimes } \\
\text { least useful as } \\
\text { could buy } \\
\text { Kits not big } \\
\text { enough }\end{array}$ & $\begin{array}{l}\text { Yes - FGD } \\
\text { Modifications to } \\
\text { quality of goods } \\
\text { Repeat sanitary } \\
\text { towels and info } \\
\text { Also matrix } \\
\text { ranking }\end{array}$ & $\begin{array}{l}\text { Yes (quantitative } \\
\text { but delayed for } \\
\text { initial } \\
\text { implementation) }\end{array}$ & $\begin{array}{l}\text { Often has to be } \\
\text { done informally } \\
\text { through } \\
\text { volunteers and } \\
\text { need permission } \\
\text { for each visit } \\
\text { Have just } \\
\text { completed an } \\
\text { assessment for } \\
\text { formal PDM in } \\
\text { Aleppo - to send } \\
\text { report }\end{array}$ & & $\begin{array}{l}\text { Yes - hired } \\
\text { enumerators } \\
\text { Aquatabs and } \\
\text { sanitary pads } \\
\text { least useful } \\
\text { also qualitative } \\
\text { data }\end{array}$ & $\begin{array}{l}\text { Yes (but delayed for } \\
\text { initial } \\
\text { implementation) }\end{array}$ \\
\hline
\end{tabular}




\begin{tabular}{|c|c|c|c|c|c|c|c|}
\hline $\begin{array}{l}\text { Received } \\
\text { hygiene kits from } \\
\text { other } \\
\text { organizations? }\end{array}$ & & & No & $\begin{array}{l}\text { No - in fact not } \\
\text { well coordinated } \\
\text { and many people } \\
\text { not receiving or } \\
\text { not receiving } \\
\text { regularly }\end{array}$ & No & $\begin{array}{l}48 \% \text { double } \\
\text { distributions } \\
\text { (from PDM) }\end{array}$ & \\
\hline Digital & & & No & & No & $\begin{array}{l}\text { Smart phone } \\
\text { AKVO }\end{array}$ & Not sure \\
\hline $\begin{array}{l}\text { Findings } \\
\text { /adaptations }\end{array}$ & $\begin{array}{l}\text { Yes - older } \\
\text { women } \\
\text { requesting more } \\
\text { underwear. } \\
\text { Changed from } \\
\text { location to } \\
\text { location. } 71 \% \text { felt } \\
\text { soap not useful } \\
\text { as can afford it. }\end{array}$ & $\begin{array}{l}\text { Separate kits for } \\
\text { each location } \\
\text { Added smaller } \\
\text { bucket for when } \\
\text { pregnant }\end{array}$ & $\begin{array}{l}\text { Yes from kits to } \\
\text { vouchers }\end{array}$ & $\begin{array}{l}\text { Some } \\
\text { modifications } \\
\text { where need } \\
\text { identified - had } \\
\text { not realized } \\
\text { demand for } \\
\text { nappies }\end{array}$ & $\begin{array}{l}\text { Kits to vouchers } \\
\text { Adoption to } \\
\text { women's } \\
\text { preferences } \\
\text { particularly for } \\
\text { women group } \\
\text { members (2016) }\end{array}$ & $\begin{array}{l}\text { Diapers for } \\
\text { children and } \\
\text { older people } \\
\text { Dignity kits with } \\
\text { underwear, } \\
\text { toilet paper and } \\
\text { shaving kits } \\
\text { reusable pads }\end{array}$ & $\begin{array}{l}\text { From IDP to host } \\
\text { targeting where } \\
\text { funding allowed }\end{array}$ \\
\hline \multicolumn{8}{|l|}{$\begin{array}{l}\text { Reporting and } \\
\text { communication }\end{array}$} \\
\hline Other & $\begin{array}{l}\text { Air drop in Nyal in } \\
2015\end{array}$ & $\begin{array}{l}\text { Lack of capacity } \\
\text { to do cash-based } \\
\text { approach }\end{array}$ & & & & & \\
\hline $\begin{array}{l}\text { Protection risk } \\
\text { analysis? }\end{array}$ & & & No & & & & \\
\hline
\end{tabular}




\section{NOTES}

1 Based on community preferences, market capacity at different times of the year, etc.

2 The definitions relating to the use of cash and vouchers are those used by the Cash Learning Partnership (CaLP) and European Civil Protection and Humanitarian Aid Operations (ECHO) in their funding guidelines, where conditionality refers to the requirements that someone has to meet to receive the cash or voucher, e.g. working or attending training. Restriction refers to the utilization of the cash or voucher. By default, vouchers are restricted transfers, but can be value-based so that people can buy certain items up to an agreed value, or commodity-based with people only able to obtain specific goods.

3 In IFRC, relief teams are responsible for NFI distribution in large-scale emergencies.

4 All data obtained from OPAL.

5 The Office of US Foreign Disaster Assistance (OFDA) and the UK Department for International Development (DFID) have recently funded PCMAs in numerous countries including Indonesia, Bangladesh, Zimbabwe, Somalia and Mozambique.

6 Based on community preferences, market capacity at different times of the year, etc. 
This paper was written by Suzanne Ferron. The author would like to extend her sincere thanks to all of those willing to give up their time to discuss this important issue. Oxfam acknowledges the assistance of Marion O'Reilly, Eva Niederberger, Sophie Caussanel, Lucy Knight and Foyeke Tolani in its production.

For more information, or to comment on this report, email Marion O'Reilly at moreilly@ght.oxfam.org

This publication is copyright but the text may be used free of charge for the purposes of advocacy, campaigning, education, and research, provided that the source is acknowledged in full. The copyright holder requests that all such use be registered with them for impact assessment purposes. For copying in any other circumstances, or for re-use in other publications, or for translation or adaptation, permission must be secured and a fee may be charged. Email policyandpractice@oxfam.org.uk

The information in this publication is correct at the time of going to press.

Published by Oxfam GB for Oxfam International under ISBN 978-1-78748-029-2 in August 2017.

Oxfam GB, Oxfam House, John Smith Drive, Cowley, Oxford, OX4 2JY, UK.

DOI: $10.21201 / 2017.0292$

\section{OXFAM}

Oxfam is an international confederation of 20 organizations networked together in more than 90 countries, as part of a global movement for change, to build a future free from the injustice of poverty. Please write to any of the agencies for further information, or visit www.oxfam.org

Oxfam America (www.oxfamamerica.org) Oxfam Australia (www.oxfam.org.au) Oxfam-in-Belgium (www.oxfamsol.be) Oxfam Brasil (www.oxfam.org.br) Oxfam Canada (www.oxfam.ca) Oxfam France (www.oxfamfrance.org) Oxfam Germany (www.oxfam.de) Oxfam GB (www.oxfam.org.uk) Oxfam Hong Kong (www.oxfam.org.hk) Oxfam IBIS (Denmark) (www.ibis-global.org)
Oxfam India (www.oxfamindia.org) Oxfam Intermón (Spain) (www.oxfamintermon.org) Oxfam Ireland (www.oxfamireland.org) Oxfam Italy (www.oxfamitalia.org) Oxfam Japan (www.oxfam.jp) Oxfam Mexico (www.oxfammexico.org) Oxfam New Zealand (www.oxfam.org.nz) Oxfam Novib (Netherlands) (www.oxfamnovib.nl) Oxfam Québec (www.oxfam.qc.ca) Oxfam South Africa (www.oxfam.org.za) 